\title{
Neurovascular injury in supracondylar fracture of Humerus
}

\author{
Shrestha K R, Sapkota R, Rajbhandari N, Thapa B, Shrestha U K \\ Department of Cardiothoracic and Vascular Surgery, Manmohan Cardiothoracic Vascular and Transplant Centre, Institute \\ Of Medicine, Maharajgunj, Kathmandu.
}

Correspondence address: Dr Kajan Raj Shrestha, MBBS, MS, MCh Resident, Department of CardioThoracic Vascular Surgery, Manmohan Cardiothoracic Vascular and Transplant Centre, Kathmandu, Nepal.

Email: kajanrs@ hotmail.com

\begin{abstract}
Introduction: Supracondylar fractures of the humerus are the commonest upper limb fractures in children, accounting for up to $70 \%$ of all pediatric elbow fractures. Supracondylar fractures of the humerus can be managed in outpatient setting but are often complicated by neurovascular injury.

Methods: Retrospective study including 187 patients who had presented with supracondylar fracture of humerus with 47 neurovascular injuries during the period of July 2007 to June 2011. Out of 142 patients with Gartland type III fracture 107 underwent immediate open reduction, exploration and internal fixation.

Results: Vascular injury is commonly associated with type II supracondylar fracture with posterior displacement. Twenty two patients had vascular injury and all of them had satisfactory outcome after surgery.
\end{abstract}

Conclusion: A careful clinical evaluation, urgent surgical treatment and adequate fracture reduction can prevent lifelong handicap.

Keywords: Pulseless hand, Supracondylar fracture, Vascular injuries.

\section{Introduction}

Supracondylar fracture of humerus is a common childhood injury involving $17.9 \%$ of all fractures in children.1 Though not common among adults, supracondylar fracture does occur in adults as a consequence of injury. This type of fracture accounts for 60 to $75 \%$ of all fractures around elbow joint in children and just about 4 to $5 \%$ in adults. ${ }^{1,2}$ The incidence reaches a peak about the age of 7 to 8 years. ${ }^{2,3}$ Typically fracture occurs due to fall in outstretched hand with hyperextension of the elbow joint. The distal fragment displaces posterior in more than $90 \%$ cases. In such fractures, both primary and secondary (iatrogenicduring manipulation) neurovascular lesions may occur. Acute vascular injury may be present in approximately $10 \%$ of cases with supracondylar fractures. Brachial artery injury may occur in the form of entrapment, spasm of the vessel, intimal tear with thrombus formation and division. On the other hand relative incidence of nerve injury is $12-20 \%$ which is mainly neuropraxia and it resolves spontaneously. ${ }^{4}$ Thus it is imperative that the early signs of vascular compromise be looked for and treated aggressively to prevent severe disability. The purpose of this study was to determine the incidence and outcome of supracondylar fracture with signs of ischemia.

\section{Methods}

Retrospective study of all patients attending Tribhuvan University Teaching Hospital(TUTH) emergency and intervened in operating room with supracondylar fracture of humerus from July 2007 to June 2011. Datas were 
obtained from OT record book and Medical record section of TUTH. There were total of 187 cases attending TUTH with supracondylar fracture. Age, sex, type and laterality of supracondylar fracture, findings of clinical and radiological assessment of vascular system, type of surgical intervention, and type of vascular injury identified and results of repair were recorded.

The cases were initially assessed by our orthopedics on duty team and vascular team was called when probable need of surgical intervention was identified. The limb is assessed for distal vascularity clinically and radiologically. Signs of vascular compromise- cold and clammy periphery, absence of radial pulse, decreased or absent capillary refill, failure to record arterial oxygen saturation, and absence of wave form in arterial Doppler were carefully looked for to suspect vascular involvement. Absence of vascularity was confirmed by on duty radiologist by a screening Doppler scan of the limb and documented. Doppler wave form, triphasic flow and pulse must be recorded to describe as good vascularity. In cases with absent distal pulsation discovered intraoperatively after reduction of fracture, vascularity was assessed intraoperatively with hand held Doppler by the vascular team themselves.

Fracture was reduced by open or closed method as deemed appropriate by the treating orthopaedics team. Vascular intervention was done when there was no perceivable improvement in vascularity despite optimal fracture reduction.

Artery was exposed anteriorly. The vessel was proximally and distally isolated and taken control of. Nature of injury was documented. The brachial artery was repaired in all cases of rent, contusion, intimal tear with thrombus formation or transection. For spasm exploration with release of fascia was done; for thrombosis - thrombosed segment was excised and end to end anastomosis was done. In cases where the vessel had been entrapped, it was freed. Primary repair with end to end anastomosis was done wherever possible with prolene 6.0/7.0 and in others reverse saphenous vein graft was used. After the repair distal pulses were assessed clinically, with saturation probe and Doppler ultrasound. Satisfactory vascularity was confirmed when distal pulses reappeared or pulse oximeter showed good waveform. The distal pulses are also assessed after closure of skin to confirm absence of compartment type of physiology. In such cases wound was left open or loosely closed for secondary wound closure. Fasciotomy was done when there was significant swelling and chance of compartment syndrome. If nerves were found to be injured, they were also repaired at the same sitting using prolene/ nylon 7.0/8.0. Heparin bolus (2500- 5000U) dose was administered during and continued (@ 50U/ $\mathrm{kg} / \mathrm{hr}$ ) postoperatively for $24-48 \mathrm{hrs}$. Immediately after restorement of distal vascularity, mannitol $250-300 \mathrm{mg} /$ $\mathrm{kg}$ iv bolus was given to prevent reperfusion injury. After the surgical exploration, the elbow was immobilized with plaster cast from hand to just below shoulder for 4 weeks. After the procedure blood supply to upper limb was reevaluated in operation theatre and thereafter in ward in daily basis.

Outcome was assessed as warm upper limb with palpable radial pulse with good pulse wave in pulse oximeter and reading above $80 \%$ without oxygen supply. Neurological status was also recorded.

All patients with associated nerve injury were also repaired in the same sitting wherever possible. In those in whom repair was not possible electromyography was done in postoperative period and managed later by orthopaedic team.

\section{Result}

There were total of 187 cases of supracondylar fracture of humerus with 125 males and 62 females $(66.85 \%$ vs $33.15 \%)$. Left sided supracondylar fracture (107/187) was found to be common than right sided (80/187) which accounted for $57 \%$ vs $43 \%$. Among 138 cases, 107 patients underwent open reduction with internal fixation with $\mathrm{K}$ wire while in 78 patients fracture was reduced by closed reduction.

Table 1: Incidence and Type of Supracondylar fracture

$\begin{array}{lll} & \text { NO OF PATIENTS } & \text { PERCENTAGE } \\ \text { TYPE I } & 4 & 2.1 \\ \text { TYPE II } & 41 & 21.9 \\ \text { TYPE III } & 142 & 76.0 \\ & 187 & 100\end{array}$

Out of 187 patients, there were 22 isolated vascular injuries and 36 isolated nerve injuries. Thus the incidence of vascular injury was $11.76 \%$ while that of nerve injury was $19.25 \%$ among the patients with supracondylar fracture presenting to out hospital. 
Table 2: Association of type of vascular injury with type of repair and nerve injury

$\begin{array}{llll}\begin{array}{c}\text { Type of } \\ \text { repair }\end{array} & \begin{array}{c}\text { Type of } \\ \text { injury }\end{array} & \begin{array}{c}\text { Associate } \\ \text { nerve } \\ \text { injuries }\end{array} & \begin{array}{c}\text { Number } \\ \text { of patients }\end{array} \\ \text { Repair } & \begin{array}{l}\text { Tear } \\ \text { Rent }\end{array} & \begin{array}{l}\text { Median nerve } \\ \text { Brachial } \\ \text { plexus }\end{array} & 2 \\ & \text { Contusion } & \text { Median and } & 8 \\ & \text { Spasm }+ & \text { Median nerve } & 3 \\ & \text { rent } & & \\ \text { Exploration } & \text { Spasm } & \text { Radial nerve } & 5\end{array}$

Table 2 shows that isolated rent is more common in older patient while tear, contusion and spasm with rent were more common in younger age group. It also shows that there is no predilection of particular nerve injury to any particular type of vascular injury. The commonest procedure performed is repair of brachial artery for contusion. Usually end to end anastomosis is possible during repair but if it is not possible then reverse saphanous vein graft can be used to restore the continuity.

Table 3: Incidence of Neurovascular injury

$\begin{array}{|ccc|}\begin{array}{c}\text { Age } \\ \text { group } \\ \text { (yrs) }\end{array} & \begin{array}{c}\text { Number of vascular } \\ \text { injury }\end{array} & \begin{array}{c}\text { Number of } \\ \text { nerve injury }\end{array} \\ <5 & 1 & 1 \\ 5-10 & 15 & 25 \\ 11-15 & 3 & 4 \\ 16-20 & 0 & 2 \\ 21-25 & 1 & 1 \\ >25 & 2 & 3 \\ & 22 & 36\end{array}$

Median age of vascular injury 7.5 yrs while median age of nerve injury was $7 \mathrm{yrs}$.

Table 4: Classification according to type of vascular injury

\begin{tabular}{lcc}
\multicolumn{1}{c}{$\begin{array}{c}\text { Type of vascular } \\
\text { injury }\end{array}$} & $\begin{array}{c}\text { Number of } \\
\text { patient }\end{array}$ & Percentage \\
Contusion & 8 & 36.36 \\
Spasm & 11 & 50 \\
Rent & 7 & 31.82 \\
Tear/ Transection & 2 & 9.09
\end{tabular}

Out of 22 patients with vascular injury, 7 patients had nerve injury too $(31.82 \%)$, Hence associated neurovascular injury is common in supracondylar fracture. On reviewing the incidence of nerve injury with supracondylar fracture, it seemed to be more common than vascular injury (36 out of $187,19.25 \%)$.

Table 5: Incidence of nerve injury

\begin{tabular}{|c|c|c|c|}
\hline $\begin{array}{c}\text { Nerve } \\
\text { involved }\end{array}$ & $\begin{array}{c}\text { Number } \\
\text { (n) }\end{array}$ & $\begin{array}{c}\text { Percentage } \\
(\%)\end{array}$ & $\begin{array}{c}\text { Associated } \\
\text { vascular } \\
\text { injury }\end{array}$ \\
\hline Brachial plexus & 1 & 2.78 & 1 \\
\hline Ulnar & 2 & 5.56 & 0 \\
\hline PIN & 2 & 5.56 & \\
\hline Radial & 13 & 36.11 & 2 \\
\hline Median & 19 & 52.78 & 4 \\
\hline Total & 36 & 100 & 7 \\
\hline
\end{tabular}

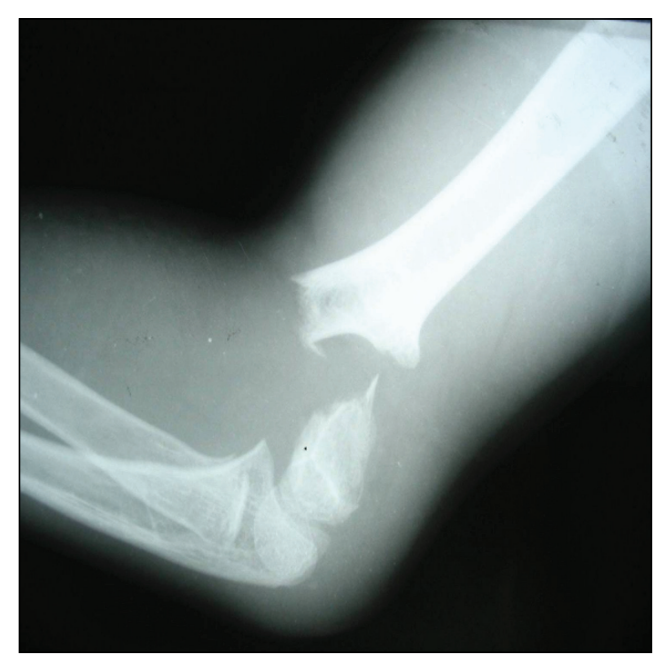

Fig. 1: Supracondylar fracture of Humerus

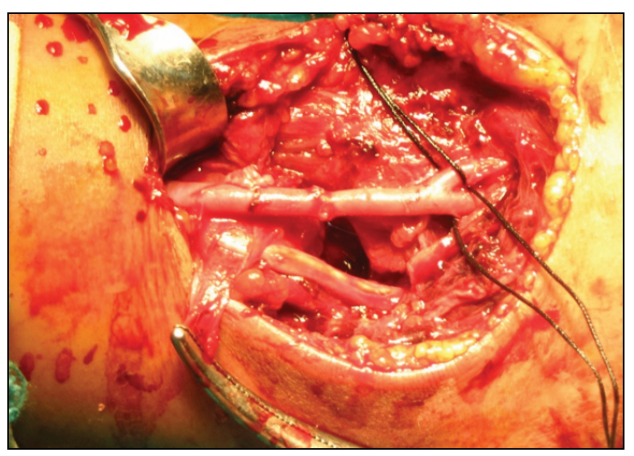

Fig. 2: Brachial artery after repair 


\section{Discussion}

Based on mechanism, supracondylar fractures of the humerus can be classified into extension fractures, which represent $97.5 \%$ of all cases, and flexion fractures, representing the remaining $2.5 \%$. Supracondylar fracture of the humerus especially Gartland III fractures when associated with vascular compromise, constitutes a true emergency. The swelling associated with this fracture may delay early detection of ischemic signs. ${ }^{5}$ This delay can lead to disastrous consequences like Volkmann's contracture, gangrene and even amputation. ${ }^{6}$ By the time the classic five P's (pain, pulselessness, parasthesias, paralysis and pallor) appear, tissue ischaemia is well established and irreversible. However, they may be noted early and can be helpful in guiding the management of vascular injury. ${ }^{7}$ The findings on examining the radial pulse are difficult to interpret. The absence of a pulse is not necessarily a danger sign and its presence not a guarantee that ischaemia will be avoided. ${ }^{8}$ The entire clinical examination must therefore be carefully considered before deciding about the vascular status. Ecchymosis in the antecubital fossa, consistent with buttonholing of the brachialis muscle and posterolateral displacement on radiography, points towards the potential of neurovascular injury and demands special attention. ${ }^{9,10}$

Rupture of the brachial artery in supracondylar fracture is rare. Spear and Janes record their impression that this injury is more common than the scarcity of literature would suggest. It is worth noting that arterial rupture seems rather more common in association with dislocation of the elbow. ${ }^{11}$

Complete substance tear or penetration of the brachialis is essential for the vessel to be injured. Closed manipulation then cannot be expected to be successful and the return of a palpable pulse does not guarantee that ischemia will be avoided.

Arterial spasm has a similar clinical presentation as that of true vascular injury. Wray ${ }^{12}$ tried local application of papaverine and pre or intraoperative stellate ganglion block. In cases of only vascular spasm, immediate surgery with exploration will not cause any additional morbidity and the patient will have normal vascular status and normal range of elbow motion postoperatively. Ottolenghi ${ }^{13}$ reported similar results, with all the cases of Volkmann's ischaemia occurring where exploration was delayed beyond 24 hours after injury. This was convincing evidence that prompt exploration can markly decrease the incidence of the dreaded vascular complications.

Radiographic evaluation of the vascular lesion included both invasive and non-invasive techniques. Doppler, magnetic resonance angiography and colour-flow duplex scanning are non-invasive techniques that may obtain anatomically and hemodynamically useful information. Angiography is an invasive technique that can be performed either before surgery in the angiography suite or in the operating room, with the aid of a C-arm. ${ }^{14}$ Its role in the investigation of an absent radial pulse is still under debate. ${ }^{15,16}$ Pre-operative evaluation based on a thorough clinical examination with the aid of Doppler ultrasonography is considered to be sufficient in evaluating the patency of the brachial artery. Nevertheless, angiography requires general anaesthesia of the patient and takes several minutes to perform, even in the hands of an expert radiologist. Magnetic resonance angiography and colour-flow duplex are safe and valid techniques that may be used after surgery to assess the patency of the brachial artery.

Sabharwal et al. ${ }^{17}$ supported the view that the combination of segmental pressure monitoring, colourflow duplex ultrasound and magnetic resonance angiography are sufficient evaluation tools for the patency of the brachial artery. On the contrary, some authors believe that these techniques do not have the specificity and sensitivity of angiography. ${ }^{18}$ The latter is sufficient to define the extension and localization of the vascular injury and provide the necessary information for the surgical plan. ${ }^{14}$ Copley et al. ${ }^{7}$ reported that a formal angiography should be performed before surgery if either the pulseless limb has no clinical signs of severe ischaemia and the essence or location of the vascular injury remains unknown due to previous vascular pathology or combined limb trauma, or when a surgical exploration is being debated. Furthermore, intra-operative arteriography with the aid of a C-arm is a useful tool in cases in which the radial pulse is not palpable after an attempt of fracture reduction. ${ }^{14}$ The same authors hold that the only contraindications for intraoperative arteriography are Gustilo type I and II open fractures, as well as severe ischaemia of the limb. Luria et $\mathrm{al}^{14}$ stated that angiography is a helpful procedure that may prevent unnecessary exploration of the brachial artery, as in the case of arterial spasm. However, angiography may not be sufficient to distinguish arterial spasm from an intimal tear (e.g. in the case of coexistence), which necessitates surgical intervention.

Nerve injuries associated with supracondylar fractures occur primarily due to tenting or entrapment of the nerve within the humeral fragments. These injuries usually recover spontaneously and have a good prognosis and surgical exploration should be retained for selected cases. Nerve injury with coexisting ischaemia is considered as an indication for nerve exploration. ${ }^{19}$ 
Other indications include a complete nerve lesion or a lesion that deepens progressively, a nerve injury during reduction or stabilization of the fracture, and the presence of persistent neuropathic pain. ${ }^{19}$ Luria et al. ${ }^{14}$ found a statistically significant correlation between the median nerve injury and the brachial artery lesion. However, they did not notice a correlation between the type of vascular lesion and nerve injury. Rupture of the median nerve in supracondylar fracture is even rarer than arterial rupture. However vascular injuries are emergencies while nerve injuries can be dealt later.

\section{Conclusion}

In cases with suspected vascular compromise following supracondylar fracture of the humerus, immediate exploration should be performed. With early stabilization of the fracture and repair of the brachial artery, long-term vascular injury sequelae can be prevented. Despite advances in technology, clinical examination still remains the most valuable tool for assessing vascular insufficiency. However a thorough Doppler examination is a good and expeditious way to identify such injuries.

\section{References}

1. Canale ST. Fractures and dislocations. In: Canale ST, Beaty JH. Operative pediatric orthopaedics. 2nd ed. St. Louis: Mosby - Year Book; 1995; 913-1112.

2. Wilkins KE. Supracondylar fractures. In: Rockwood ChA, Wilkins KE, King RE. Fractures in children. 3rd ed. Philadelphia: J B Lippincott Company; 1991; 526-617.

3. Devito DP. Suppracondylar fracture. In: Morrisy RT, Weinstein SL, editors. Lovell and Winter's pediatric orthopaedics. 4th ed. Philadelphia: Lippincott-Raven publishers; 1996. 1242-1247

4. Kumar R, Trikha V, Malhotra R. A Study of Vascular Injuries in Paediatric Supracondylar Humeral Fractures. J of Ortho Surg 2001, 9;2:37-40.

5. Kurer MHJ, Regan MW. Completely displaced supracondylar fracture of the humerus in children. Clin Orthop 1990; 256:205-214

6. Pirone AM, Graham HK, Krajbich JI. Management of displaced extension type supracondylar fractures of the humerus in children. J Bone Joint Surg 1988; 70A, 641-650

7. Copley LA, Dormans JP, Davidson

RS. Vascular Injuries and their sequelae in pediatric supracondylar humeral fractures: Towards a goal of prevention. J. Pedia. Orthop 1996, 16:99-103

8. Blount WP. Fractures in children. Am Acad Orthop Surg. Instructional Course Lectures, JW Edwards, Inc. Ann Arbor, 1950; 7:194-202

9. Friedman RJ \& Jupiter JB. Vascular injuries and closed extremity fractures in children. Clin Orthop 1984; 188:112-119

10. Spencer AD. The reliability of signs of peripheral vascular injury. Surg Gynecol Obstet 1962; 114:490

11. Spear HC and Jane JM. Rupture of the Brachial Artery Accompanying Dislocation of the Elbow or Supracondylar Fracture. Journal of Bone and Joint Surgery, J of Bone and Joint Surg 1951; 33;889-894

12. Wray J. Management of supracondylar fractures with vascular insufficiency. Arch Surg 1965; 90:279-285

13. Ottolenghi CE. Acute Ischaemic Syndrome: Its treatment, prophylaxis of Volkman's Syndrome. Am J Orthop 1960; 2:312-316.

14. Luria S, SucarA, Eylon S, Pinchas-Mizrachi R, Berlatzky Y, AnnerH, Liebergall M, Porat S Vascular complications of supracondylar humeral fractures in children. J Pediatr Orthop B 2007; 16:133-143

15. Clement DA: Assessment of a treatment plan for managing acute vascular complications associated with supracondylar fractures of the humerus in children. J Pediatr Orthop 1990; 10: $97-$ 100

16. Shaw BA, Kasser JR, Emans JB, Rand FF. Management of vascular injuries in displaced supracondylar humerus fractures without arteriography. J Orthop Trauma 1990; 4:25-29

17. Sabharwal S, Tredwell SJ, Beauchamp RD, Mackenzie WG, Jakubec DM, Cairns R, LeBlanc JG. Management of pulseless pink hand in pediatric supracondylar fractures of humerus. J Pediatr Orthop 1997; 17:303-310

18. Schuler JJ, Flanigan DP, Meyer JP. Combined vascular and orthopedic injuries. In: Flanigan DP (ed) Civilian vascular trauma. Lea \& Febiger, Pennsylvania, 1992; 265-267

19. Ramachandran M, Birch R, Eastwood DM. Clinical outcome of nerve injuries associated with supracondylar fractures of the humerus in children: the experience of a specialist referral centre. $J$ Bone Joint Surg Br 2006; 88:90-94 